\title{
Assessment of Nurses' Knowledge and Attitude about Hypoglycemia at
}

\section{Mosul City Hospital}

Yasir Mohammed Altahan *

Nabeel Najeb Fadhil **

\section{ABSTRACT}

Background and aim:- Hypoglycemia, one of the acute complications of diabetes mellitus, It carries a lot of adverse effects on the patient psychic and mental state plus the bad sequels on the cardiovascular system and central nervous system that may prove to be fatal. Nurses, working in hospitals, are supposed to be reasonably educated and skillful in detecting hypoglycemia and presenting the first aids that may save the patients' life. In Mosul's hospitals, the knowledge and attitude of nurses about hypoglycemia have not been explored or assessed, a matter that was motivating to study this issue. So, this study aimed to assess of Nurses' Knowledge and Attitude About Hypoglycemia at Mosul City Hospitals.

Materials and method: A descriptive cross sectional study carried throughout the period $2^{\text {nd }}$ of December 2013 -to- $31^{\text {st }}$ of January 2015 . The sample of the study was a non-probability convenience sample which included 247 nurses (males and females) working in six teaching hospitals in Mosul. The data were analyzed using the statistical package for social science (SPSS) program version 17 throughout the application of descriptive statistic (frequency, mean, standard deviation and percentage) and inferential statistics (t-test and ANOVA-one way test).

Results:- The findings of the study indicated that the total nurses' knowledge concerning hypoglycemia was found to be highly significant. However, the mean scores gained in different knowledge categories were moderate except that of causes and risk factors were low. The positive nurses' attitude toward hypoglycemia was found to be highly significant. Also the study showed that there are significant correlation between nurses' knowledge scale and attitude scale.

Conclusions:- There are significant differences in nurses' knowledge but, mean score answers in regard to knowledge categories were moderate except that of causes and risk factors was low. also the differences was significant in relation to positive attitudes. Recommendation:- The study recommends preparing, developing and implicating educational programs about hypoglycemia; its complications in Mosul's hospitals. In addition, the study suggests improving the curriculum in regard to diabetes and its complications.

Keywords: Nurses', Knowledge, Attitude, Hypoglycemia.

\section{INTRODUCTION}

Diabetes mellitus (DM) is a chronic disease that requires continuous medical care and self-management education to prevent acute complications and prevent the risk of long term complications (American Diabetes Association, 2013). People with diabetes are at risk of developing a number of disabling and lifethreatening health problems (Cho et. al., 2013) which included long term and acute complications. Long term complications are subdivided into microvascular complications such as (retinopathy, nephropathy) and macrovascular complications (atherosclerosis), in addition to foot complication and neuropathic complications as (mononeuropathy, polyneuropathy and autonomic neuropathy). Acute complications consist of (hypoglycemia, diabetic ketoacidosis -DKA- and hyperosmolar hyperglycemic nonketotic syndrome- HHNS) (Linton, 2012).

Hypoglycemia, which is one of the acute complications of DM is defined as a blood glucose level of less than $70 \mathrm{mg} / \mathrm{dL}$ (Pagana and Pagana, 2010), is a major barrier to intensive glycemic control (Davis and Alonso, 2004). and affects $7.7 \%$ of diabetes hospital admissions (Turchin et. al., 2009). Hypoglycemic events are common, and are associated with both increased length of stay and mortality (Ellis et al; 2013). and is a barrier to initiating, intensifying, and optimizing therapy, as well as long-term adherence (Penny and Michael, 2012). It was also found to be associated with an increased risk of death (Bonds et. al., 2010).

For diabetic patients, hypoglycemia is a fact of life. About $90 \%$ of all patients who receive insulin have experienced hypoglycemic episode. The reported incidence of hypoglycemia differs considerably among studies, however, in general, T1DM patients have an average of two episodes of symptomatic hypoglycemia per week and one episode of severe hypoglycemia once a year. An estimated

\footnotetext{
* MSc Candidate/ Nineveh Health Dicroterate.

** Assistant Professor / College of Medicine/ University of Nineveh.
} 
$2-4 \%$ of deaths of this population have been attributed to hypoglycemia as documented throughout (Cryer et. al., 2009 and Cryer, 2004).

Symptoms known to be caused by hypoglycemia may range from a benign increased appetite or feeling hungry at the time before the mealtimes to severe symptoms like drenching sweating, blurred vision, abnormal behavior, convulsions, unconsciousness and coma as documented throughout Cryer et. al. in 2009 and cited by (Sandhua et. al.; 2011).

Hypoglycemia is a true medical emergency which requires prompt recognition and treatment to prevent organ and brain damage. The spectrum of symptoms depends on duration and severity of hypoglycemia and varied from autonomic activation to behavioral changes to altered cognitive function to seizures or coma. The short and long term complications of hypoglycemia include neurologic damage, trauma, cardiovascular events and death (Shefiee et. al., 2012).

Severe untreated hypoglycemia can cause a significant economic and personal burden, therefore identification and prevention of hypoglycemia can reduce diabetes burden by prevention of hypoglycemia complications (Shefiee et. al., 2012).

The majority of hypoglycemic episodes are managed by nurses (Stanisstreet et. al., 2010). Hypo-boxes were introduced, as well as hypoglycemia management guidelines and staff training to standardize hypoglycemia management (Chinnasamy et. al; 2011). Guidelines to manage hypoglycemic episodes have been developed to allow nurses to intervene immediately without having to contact the physician first (Rycroft-Malone et. al, 2009). therefore, a study to assess their knowledge and explore their attitudes toward this lifethreatening complication emerges.

\section{RESULTS}

(A) Characteristics of the sample:

Socio-demographic characteristics of the nurses:

Table (1): Socio demographic characteristics of the sample: $(N=247)$.

\begin{tabular}{||l|c|c|}
\hline Variable & No. & \% \\
\hline \hline $\mathbf{( 1 ) G e n d e r ~}$ & 151 & 61.10 \\
\hline Male & 96 & 38.90 \\
\hline Female & 247 & 100 \\
\hline Total & 6 & 2.40 \\
\hline (2)Age & 82 & 33.20 \\
\hline Less than 20 years & \multicolumn{2}{|l|}{} \\
\hline 20-29 years & \multicolumn{3}{|l|}{} \\
\hline
\end{tabular}

\section{MATERIALS AND METHOD}

A descriptive, cross sectional design was carried out during the period between December 2013 -to- January 2015 in different medical, surgical, gynecologic and pediatric wards, and causality and dialysis units in Mosul Teaching Hospitals including: (Ibn-Sina, Al-Jumhuri, AlBatool, Assalam, Ibn-Alather, Al-Khansaa). Non-probability convenience sample was chosen for the current study. The sample consisted of 247 nurses. A special questionnaire was constructed, and interview method was used to gather the data concerning the subject of the study. The questionnaire was designed by the researcher making use of literature review, opinion of supervisor, opinion of experts and pilot study. It consisted of 8 questions for demographic data, 48 questions divided into 6 categories for knowledge field and 12 questions for attitude field, each item of knowledge and attitudes has three options (Incorrect answer=0; Uncertain or "neutral in attitude" $=1$; Correct answer= 2). To fulfill it, each interview with each participant lasted a period of time between 15-25 minutes. The validity of the questionnaire was determined by exposing it to 20 specialized experts in different fields of sciences, whereas, their comments was followed in the final draft of the tool, while its reliability was checked through application on 10 nurses who were working in Ibn-Sina Teaching Hospital - who were excluded from the final sample of the study - for a period of between 20th of January 2014 to- 3rd of February 2014, and by using Pearson's Coefficient Correlation, the outcomes were 0.82 and 0.79 for the knowledge and attitude fields respectively. The data were analyzed using the statistical package for social science (SPSS) program version 17 throughout the application of descriptive statistic (frequency, mean, standard deviation \& percentage) and inferential statistics (t-test and ANOVA-one way test). 


\begin{tabular}{||l|c|c||}
\hline 30-39 years & 96 & 38.90 \\
\hline 40-49 years & 39 & 15.80 \\
\hline $50-59$ years & 21 & 8.50 \\
\hline$\geq 60$ years & 3 & 1.20 \\
\hline Total & 247 & 100 \\
\hline (3)Educational level & 10 & \multicolumn{2}{||}{} \\
\hline Intermediate Nursing School graduate & 108 & 44 \\
\hline Secondary Nursing School graduate & 90 & 36 \\
\hline Nursing Institution graduate & 36 & 15 \\
\hline Nursing College graduate & 3 & 1 \\
\hline Higher studies graduate in Nursing & 0 & - \\
\hline Others & 247 & 100 \\
\hline Total & \multicolumn{2}{|l|}{} \\
\hline (4)Site of Work & 40 & 16.20 \\
\hline Aljumhory Teaching Hospital & 48 & 19.40 \\
\hline Ibn Sina Teaching Hospital & 42 & 17 \\
\hline Assalam Teaching Hospital & 38 & 15.40 \\
\hline Ibn Alather Teaching Hospital & 42 & 17 \\
\hline Al Khanssa Teaching Hospital & 37 & 15 \\
\hline Al Batool Teaching Hospitals & 247 & 100 \\
\hline Total & \multicolumn{2}{|l}{} \\
\hline \hline
\end{tabular}

(B) Aims attainment:

(B-1) Assessment of nurses' knowledge about hypoglycemia:

Table (2): Total nurses' knowledge by using one sample T. test.

\begin{tabular}{|c|c|c|c|c|c|c|}
\hline No. & Mean & Test Value & SD $^{*}$ & T cal. $^{\dagger}$ & T tab. $^{\dagger}$ & $\boldsymbol{P}$ value \\
\hline 247 & 57.1862 & 48 & 6.31279 & 22.870 & 1.960 & 0.000 \\
\hline
\end{tabular}

* $\mathrm{SD}=$ Standard deviation

${ }^{\dagger} \mathrm{T}$ cal.= the calculated value of Student test.

$\$ \mathrm{~T}$ tab.= the tabulated value of Student test.

$\cdot \mathrm{df}=$ Degree of freedom.

Descriptive statistics of total nurses' knowledge domains.

Table (3): Descriptive statistics of total nurses' knowledge domains by using mean and standard deviation (SD).

\begin{tabular}{||l|c|c|c|c||}
\hline Categories & No. of items & $\begin{array}{c}\text { Mean of scores } \\
\text { (Test Value) }\end{array}$ & $\begin{array}{c}\text { Mean knowledge } \\
\text { Score } \pm(\text { SD) }\end{array}$ & $\begin{array}{c}\text { Knowledge } \\
\text { score in \% }\end{array}$ \\
\hline $\begin{array}{l}\text { Definition, epidemiology } \\
\text { and classification }\end{array}$ & 5 & 5 & $\begin{array}{c}7.1498 \\
\pm(1.35769)\end{array}$ & 71.50 \\
\hline Causes and risk factors & 11 & 11 & $\begin{array}{c}10.8138 \\
\pm(2.75078)\end{array}$ & 49.15 \\
\hline Signs and symptoms & 12 & 12 & $\begin{array}{c}15.4777 \\
\pm(2.90893)\end{array}$ & 64.49 \\
\hline Complication & 5 & 5 & $\begin{array}{c}5.3968 \\
\pm(1.99095)\end{array}$ & 53.97 \\
\hline Treatment and nursing care & 11 & 11 & $\begin{array}{c}12.7166 \\
\pm(2.33057)\end{array}$ & 57.80 \\
\hline Prevention & 4 & 4 & $\begin{array}{c}5.6316 \\
\mathbf{( 1 . 5 5 5 8 4 )}\end{array}$ & 70.40 \\
\hline
\end{tabular}


(B-2) Assessment of nurses' attitude about hypoglycemia:

Table (4): Total nurses' attitude by using one sample T. test.

\begin{tabular}{||c|c|c|c|c|c|c|}
\hline No. & Mean & Test Value & SD & T cal. & T tab. & P value \\
\hline 247 & 18.4261 & 12 & 2.40470 & 42.019 & 1.960 & 0.000 \\
\hline $\mathbf{d f}=\mathbf{( 2 4 6 )}, \boldsymbol{\alpha}=\mathbf{( 0 . 0 5 )}$
\end{tabular}

(B-3) Relationship between knowledge scale and attitude scale:

Table (5): Relationship between knowledge and attitude using Pearson Coefficient Correlation.

\begin{tabular}{|c|c|c|c|}
\hline Item & No. & Pearson Correlation & $P$ value \\
\hline Total & 247 & 0.196 & 0.002 \\
\hline
\end{tabular}

\section{DISCUSSION}

(A) Characteristics of the sample:

\section{Discussion of socio-demographic} characteristics of the nurses (Table 1)

The study indicates that the majority $(61.10 \%)$ of the sample were males. More than one third of the samples $(38.90 \%)$ were from the age group (30-39). About half of the samples $(44 \%)$ were secondary school graduates, (19.40\% and 16.20) of the sample working at Ibn Sina and Aljumhory Teaching Hospitals respectively (Table 1 ).

(B) Aims attainment:

(B.1) Discussion of nurses' knowledge about hypoglycemia (Table 2, 3).

Total nurses' knowledge by using one sample T. test (2).

Identification of areas of deficient knowledge among nursing staff represents an important step towards application of target educational programs and ultimately improvement of care standards for hospitalized diabetic patients in general and in regard to hypoglycemia. Results of the study indicate that the nurses' knowledge was highly significant $(P$ 0.000 ) at $P \leq 0.05$ (Table 2 ). This is, possibly due, to the high incidence of diabetes in Iraq (10.4\%) (Mostafa, and Almukhtar, 2012); that might had lead the nurses to be in high contact with its complications in hospitals, clinics and other places, a contact that impacted their knowledge favorably. This study disagrees with a study done in Libya by (Abduelkarem and El Shareif, 2013), who found that the mean score for knowledge about diabetic hypoglycemia was $47.8 \%$ which indicates a lack of nurses' knowledge about hypoglycemia.

Descriptive statistics of total nurses' knowledge categories by using mean $( \pm \mathrm{SD})$ (Table 3).

The study showed that the mean $( \pm \mathrm{SD})$ of nurses' knowledge scores ranged between low
$(<50 \%)$ and moderate $(50-75 \%)$. No any high knowledge score $(>75 \%)$ concerning hypoglycemia categories was attained by them. The highest score in \% (71.5\%) was in the category of definition and epidemiology but it was lowest $(49.1 \%)$ in the category of causes and risk factors (Table 3 ).

The mean score of definition and epidemiology with classification was 7.1498. This represented a percentage of $71.50 \%$, which reflects a moderate knowledge of nurses about this category. The finding agrees partly with the study done in Birmingham by (Thomas, 2004); who found that the correct responses about the definition of DM were $88.5 \%$, but disagrees with the percent of knowledge regarding hypoglycemia definition in the same study $(53.0 \%)$. Also, this result is dissimilar to a study done in Jordon by (Al Sarayra, and Reem, 2012), who found that about $33.75 \%$ of the students know the definition of DM, $31.2 \%$ of them considered that insulin deficiency is found in T1DM and $41.6 \%$ know that insulin dysfunction is found in T2DM.

On the other hand, the mean score of the causes and risk factor $(10.81)$ which represents a percentage of $49.15 \%$, is considered low. Deficiency in knowledge regarding the causes and risks of hypoglycemia put the nurses in a low ability to provide advice to patients how to avoid hypoglycemia in the future. This result is incongruent with the study done in the United Kingdom by (Findlow and McDowell, 2002), who found that the correct answer about the causes of hypoglycemia was (99.0\%).

The mean score of knowledge in regard to the signs and symptoms of hypoglycemia (15.47), which represents a percentage of $64.49 \%$, is considered moderate. This finding is dissimilar to the study done in the United Kingdom by (Findlow and McDowell, 2002) who found that the correct answer about the 
symptoms of hypoglycemia was $43.3 \%$. This is considered a lack in the nurses' knowledge about symptoms of hypoglycemia.

Because hypoglycemia is often seen as a main limiting or barrier to diabetes control control (Cryer, 2002), a recent meta-analysis of large cardiovascular $(\mathrm{CV})$ outcome studies in diabetes including ACCORD, ADVANCE and VADT (Veterans Affairs Diabetes Trial), suggests that there is a direct correlation between the incidence of severe hypoglycemia and CV mortality (Mannucci et. al., 2009). It is therefore essential, particularly in old people with long durations of diabetes and CV disease (CVD), to avoid severe hypoglycemia and choose therapy with the least risk of causing hypoglycemia. Thus, the knowledge of nurses and other medical specialists about complication of hypoglycemia should be adequate to avoid complications of hypoglycemia and to be able to understand the risk of hypoglycemic complication and, also, to be able to deal with and treat such complications (Chinnasamy et. al., 2011).

The nurses' knowledge of hypoglycemic complication in this study was moderate as the mean score was 5.3968, which represents a percentage of $53.97 \%$. Therefore, it is very important to enable the nurses to learn more about hypoglycemia complications. This result is dissimilar to the study done in Jordon by ( $\mathrm{Al}$ Sarayra, and Reem, 2012), who found that there is a lack of knowledge about complications of diabetes including hypoglycemia.

Regarding the treatment and nursing care, the mean score $12.7 \%$ represents a percentage of $57.80 \%$. This is considered a moderate knowledge of nurses in this category. This result is not comparable to found in a similar study done in Iran by (Peimani et al; 2010); which found that the correct answer about the treatment of hypoglycemia was presented by only $23.2 \%$ of the nurses. However, it is comparable to the study done in United Kingdom in London by (Carney, 2010), who found that $66 \%$ of nurses correctly selected glucose tablets as treatment when they were asked to select the most appropriate treatment of symptomatic hypoglycemia from many options including a small candy bar, piece of cake, ice cream or glucose tablets.

Finally, the mean score of the prevention of hypoglycemia was 5.63 that represents a percentage of $70.40 \%$, is considered a moderate knowledge of nurses in this category. This finding is dissimilar to the study done in Iran by
(Peimani et. al, 2010); who revealed that $36.2 \%$ of physicians had acceptable function in control and prevention of diabetes and its complications. Also, it is comparable to results regarding some questions in the questionnaire done in the Saudi Arabia by (Khan et. al., 2011), who found that $63.6 \%$ of physicians agreed to avoid sulphonylureas after the start of insulin to prevent hypoglycemia.

\section{(B.2) Total nurses' attitude about hypoglycemia (Table 4).}

Understanding similarities and differences in attitudes towards diabetes, its complication and its treatment is important. Beliefs and attitudes, not knowledge deficits, may be major barriers to effective practice and therapeutic outcomes for people with diabetes. Addressing these, in addition to knowledge, is likely to be more effective in changing practice behaviour and improving diabetes outcomes (Clark, 2005). Results of the study indicate that the nurses' attitude was highly significant $(P 0.000)$ at $P \leq 0.05$ (Table 4 ). The highly significant results in the field of attitudes parallel with the significant knowledge of nurses, as good knowledge lead can lead to good attitude.

\section{(B.3) Relationship between knowledge scale and attitude scale using Pearson Coefficient Correlation (Table 5):}

The study showed that there are significant correlation between nurses' knowledge scale and attitude scale at $P \leq 0.05$ (Table 5). In my viewpoint, that is because the presence of good knowledge leads to a good attitude. This outcome corroborates with the study done in Iran by (Peimani et al; 2010), who discovered a positive significant linear relationship between knowledge score and attitude $(\mathrm{r}=0.54)$. However, this finding is dissimilar to the results of a study done in Saudi Arabia by (Abdel Gawwad, 2008), who found a negative significant relationship between knowledge and attitude scores toward diabetes. It was found that those who had favorable attitudes attained the least knowledge score (27.0), while those who had neutral or unfavorable attitudes had a higher knowledge mean score (34.87 and 35.08) (F 4.041, $p$ $<0.05)$.

\section{CONCLUSION}

On the bases of the objectives of the current study and outcomes of data analysis, the following have been concluded:

The majority of the sample in the study was males, and more than one third of the 
sample ranged between the ages 30-39 years. Most of sample (44\%) was from secondary school graduates. The highest percentage of nurses was from Ibn Sina Teaching Hospital (19.4\%), while the percentage of nurses from other sites was nearly comparable $(15 \%-17 \%)$. Nurses' knowledge about hypoglycemia was highly significant. Mean score was highest in the category of definition, epidemiology with classification and lowest in the category of causes and risk factors. The posative nurses' attitude about hypoglycemia was highly significant. Correlation between total nurses' knowledge scale and total attitude scale was significant.

\section{RECOMMENDATIONS}

Based on the results of the study, the researcher recommends the following: Activating nursing continuous education, in collaboration with WHO in hospitals, and enter nurses in Mosul Teaching Hospitals by educational program concerning diabetes and its complication. Development of nursing curriculum in regard to diabetes and its complications and opening of specialties in nursing field (high diploma or certificates) in all specialization particularly diabetes to help nursing staff in resurgence to the level that qualifies them to deal with such cases. Nurses should document and follow up all hypoglycemic cases in the chart for statistical and therapeutic purposes, and they should share in dealing and treating these cases.

\section{REFERENCES}

Abdel Gawwad, E. (2008). Teacher's Knowledge, Attitudes and Management Practices about Diabetes Care in Riyadh's Schools. J Egypt Public Health Assoc. 83 (3 and 4). P.p. 205, 212.

Abduelkarem, A.; El Shareif, H. (2013). Assessment of diabetes-related knowledge among nursing staff in hospital setting. Journal of Diabetes Nursing. 17(6). P.p. 207, 210, 214.

Al Sarayra, L.; and Reem S. (2012). Awareness and Knowledge about Diabetes Mellitus among Students at Al-Balqa' Applied University. Pakistan Journal of Nutrition. 11 (11). P.p. 1023-1026.

American Diabetes Association (January, 2013). Standards of Medical Care in Diabetes 2013. Diabetes Care.36 (1). P.p. 11.

Bonds, D.; Miller, M.; Bergenstal, R.; and et. al. (2010). The association between symptomatic, severe hypoglycaemia and mortality in type 2 diabetes: retrospective epidemiological analysis of the ACCORD study. BMJ. 340.b4909. P.p. 1.

Carney, T. (2010). Knowledge, Comfort Level and the Perceived Role of Nurses in Promoting Nutritional Management of Diabetes (M.Sc. thesis.). United Kingdome (LDN): (Drexel University, College of Nursing and Health Professions, Nutrition Sciences Department. P.p. 1, 52.

Chinnasamy, E.; Mandal, M.; Khan, S.; Iqbal, F.; and Patel, N. (2011). Nurses knowledge of inpatient hypoglycaemia management. Journal of Diabetes Nursing. 15 (8). P.p. 313, 316.

Cho N., Whiting D.; Guariguata L.; Montoya P.; Forouhi N.; Hambleton I.; and et. al. (2013). IDF Diabetes Atlas. ( $6^{\text {th }}$ ed.). International Diabetes Federation. P.p. 24.

Clark, M. (2005). Healthcare professionals' versus patients' perspectives on diabetes. Journal of Diabetes Nursing. 9 (3). P.p. 87-90.

Cryer, P. (2002). Hypoglycemia: the limiting factor in the glycemic management of type 1 and type 2 diabetes. Diabetologia. 45 (7). P.p. 937.

Cryer, P. (2004). Diverse causes of hypoglycemia associated autonomic failure in diabetes. $N$ Engl J Med. P.p. 2272-2279.

Cryer, P.; Axelrod, L.; Grossman, A.; and et. al. (2009). Evaluation and management of adult hypoglycemic disorders: an Endocrine Society Clinical Practice Guideline. J Clin Endocrinol Metab. 94. P.p.718-719.

Davis, S.; Alonso, M. (January 2, 2004). Hypoglycemia as a barrier to glycemic control. JOURNAL OF DIABETES AND ITS COMPLICATIONS. 18 (1).

Ellis, D.; Ortiz, E.; Bernhardt, L.; and Skala,n K. (2013). Hypoglycemia: Not such an ordinary event. Advocate Health Care.

Findlow, L.; McDowell, J. (2002). Determining registered nurses' knowledge of diabetes mellitus. Journal of Diabetes Nursing. 6 (6). P.p. 172.

Khan, A.; Abdul-Lateef , N.; Khamseen M.; AlAithan, M.; Khan, S.; and Al-Ibrahim, I. (2011). Knowledge, attitude and practice of ministry of health primary health care 
physicians in the management of type 2 diabetes mellitus: A cross-sectional study in the Al Hasa District of Saudi Arabia, 2010. Nigerian Journal of Clinical Practice. 14(1). P.p. 52, 56, 58.

Linton, A. (2012). Introduction to MedicalSurgical Nursing. $\left(5^{\text {th }}\right.$ ed.). USA. Elsevier Saunders. P.p. 1050-1055.

Mannucci, E.; Monami M., Lamanna C., and et al., (2009). Nutr Metab Cardiovasc Dis. 19. P.p. 604, 607.

Mostafa, W.; Almkhtar, M. (2012). Quality of life of patients with type 2 diabetes mellitus in Mosul. Annals of the College of Medicine. 38(1). P.p. 21.

Pagana, K.; Pagana, T. (2010). Mosby's manual of diagnostic and laboratory tests. St. Louis, MO: Mosby Elsevier. P.p. 269-270-275.

Peimani, M.; Malazy, OT.; Heshmat R., Amirimoghaddam, S.; Sanjari M.; and Pajouhi, M. (2010). Knowledge, Attitude and Practice of physicians in the field of diabetes and its complications; A pilot study. Iranian Journal of Diabetes and Lipid Disorders. 9. P.p. 1-4.

Penny, T.; Michael, H.S. (October 2012). Managing Hypoglycemia in Primary
Care Supplement to The Journal of Family Practice. 61(10). P.p. 1-2.

Rycroft-Malone, J.; Fontenla, M.; Seers, K.; and Bick, D. (2009). Protocol based care: The standardization of decisionmaking? Journal of Clinical Nursing.18. P.p. 1490-1500.

Sandhu, G.; Rana, M.; Bashir, M.; and Rehman, A. (Mar, 2011). HYPOGLYCEMIA; EXPERIENCE IN DIABETICS. Professional Med J. 18 (1). P.p. 83.

Shafiee ,G.; Mohajeri-Tehrani, M.; Pajouhi, M.; and Larijani, B.; (2012). The importance of hypoglycemia in diabetic patients. Journal of Diabetes and Metabolic Disorders. 11(17). P.p. 1, 6.

Stanisstreet, D.; Walden, E.; Jones, C.; and Graveling, A. (2010). The Hospital Management of Hypoglycaemia in Adults with Diabetes Mellitus. NHS Diabetes. London. P.p. 7.

Thomas, E. (2004). Survey reveals shortfall in pediatric nurses' knowledge of diabetes. Journal of Diabetes Nursing. 8 (6). P.p. 219.

Turchin, A.; Matheny, M.; Shubina, M.; and et. al. (2009). Hypoglycemia and clinical outcomes in patients with diabetes hospitalized in the general ward, Diabetes Care. 32(7).P.p.1153-7. 